THE POSTGRADUATE

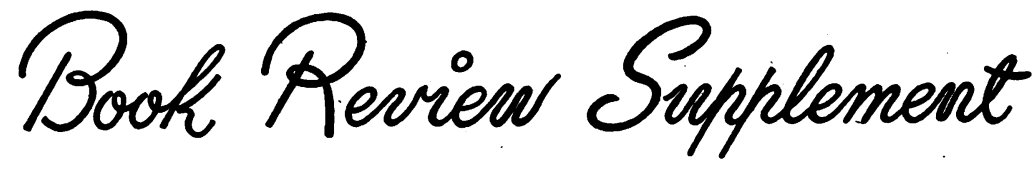

\section{REPORT OF THE MEDICAL RESEARCH COUNCIL FOR THE YEAR 1951-1952}

Pp. iv + 24I. London: H.M.S.O. I953. 6s. 6d.

This report includes a summary of the work carried out in the separate research establishments controlled by the Medical Research Council; also various statistical facts such as a list of the members of the Council and its principal committees and 66 pages are devoted to a list of the publications by the members of the Council staff.

\section{DISEASES OF THE THROAT, NOSE AND EAR}

Edited by F. W. Watkyn-Thomas, F.R.C.S. Pp. $\mathrm{xi}+880$, with 367 illustrations, 22 in colour. London: H. K. Lewis \& Co. I953. £5 ros.

The arrival of yet another new textbook on Diseases of the Ear, Nose and Throat may at first seem unnecessary. This book, however, replaces the out-dated one written by Herbert Tilley, and in so doing its editor has produced what is undoubtedly a really first-class work.

There are many noteworthy points. It is a textbook of one volume, containing an amazing amount of information suitable as the groundwork for the Final F.R.C.S. (E.N.T.) examination, as well as being a book of reference for the practising surgeon. The editor has marshalled a well-balanced team of colleagues, mostly from University College Hospital, who have followed the same pleasant, readable style of writing, with interesting reminiscences. All contributors have cut out much old and unnecessary data, making room for a vast amount of detail concerning present-day methods and opinions; the fullness of the index with references to these details is remarkable.

Several subjects not usually discussed fully in other textbooks of this specialty have been included. Outstanding in this category are the chapters on plastic techniques, the management of deafness and aviation otology. Many subjects are dealt with from a delightfully fresh aspect, with older opinions mentioned briefly. The apportioning of space is rationalized, with subjects like endoscopy occupying a brief though excellent section..

The editor has wisely borrowed many excellent plates and diagrams from the best sources, so that, with the few exceptions mentioned below, the? standard of illustration is very high. Moreover, it 3 . is a pleasure to see how well the proofs of a firstin edition have been corrected, as one misprint only was noted.

It is always possible to criticize any textbook. The poor colouration of the diagrams illustrating $N$ laryngeal conditions is very striking and far below standard; the sketch illustrating adenoids is of doubtful use. There are several statements which differ in opinion very strongly from that usually accepted, particularly by examiners. Examples are some of the ' absolute indications ' for tonsillectomy and the incision in the pharynx of a tuberculous retropharyngeal abscess. Lastly there are statgments which express controversial opinion withoutto other views being mentioned. Examples of thesec are that obstruction of nasal respiration is the 10 variable cause of maldevelopment of maxilla, hard palate and teeth; a nice picture of orthodontic abnormalities seems to suggest that they could beō the cause rather than the effect of mouth breathingo and large adenoids. Also in this category are the $\underset{\mathbb{Q}}{\mathbb{Q}}$ statements that the electric naso pharyngoscope can $\overrightarrow{\vec{P}}$ give a view of the " whole of the post-nasal space, $\frac{}{3}$ and that the sphenoid sinus is ' never' the seat of primary malignant disease.

The above remarks in no way detract from the general excellence and usefulness of this book.을 Although its price appears rather formidable, it. seems an essential acquisition both for all post-음 graduates taking examinations and for practising otorhinolaryngologists.

\section{HISTOLOGY}

By A. W. HaM, M.B., F.R.S.C. 2nd Edition? Pp. $x i x+866$, with 5 18 illustrations, 7 in colour London: J. B. Lippincott Company. 1953. 805 N It is not quite three years since the first edition of Professor Ham's 'Histology' was reviewed in this journal. The fact that a new edition is called for so soon is evidence not only of rapid advance is the science of histology, but also of the well-deserved popularity which the book has won for itself despitex its high price.

Its general plan and character is substantially un=0 altered, though additions and modifications have 
increased the number of pages by $r$ ro and the figures by 73. A considerable part of the increase in size is due to an expansion of the section dealing with the nervous system; so far as this results in a more adequate account of the cytology of the neurone and of the other constituents of the nervous system such as neuroglia, this can be welcomed unreservedly, but the addition of a little neuroanatomy, much of which is covered in elementary textbooks of biology, is of doubtful value. Several other chapters have been rewritten, notably that dealing with the cell, which now forms an excellent introduction to modern ideas and methods in cytology. The chapter on the liver has been rewritten and that on the kidney very largely rewritten. Most chapters in fact have received some addition or modification and there is no doubt that the general result has been to improve the text considerably and to bring it into closer relationship with recent advances in histological knowledge and technique. While the illustrations have also been improved, quite a large proportion of the microphotographs are less good than one would expect in a book of this price and standard of production.

It is very satisfactory that the book should have survived the modifications necessary in a second edition without losing any of the excellent qualities of the first. It remains an exceedingly readable and intelligent introduction to the study of histology, and has avoided that dreary and impersonal quality which is so characteristic of most textbooks. It is intended primarily for the undergraduate medical student, and naturally is written from the point of view of undergraduate needs and difficulties. Histology, however, enters very largely into almost all aspects of post-graduate medical work. Most post-graduates find that they need special knowledge in some aspect of the subject, and if they are not already expert histologists the relevant sections of this book will be extremely helpful. No textbook, of course, and certainly not one which is limited to a single volume, can provide the detailed knowledge of specialized aspects or applications which postgraduate work may require. It will nearly always be necessary to consult original papers, and for this the classified lists of references given at the end of each chapter will be of great value.

\section{EXTRASYSTOLES AND ALLIED ARRHYTHMIAS}

By David Scherf, M.D., F.A.C.P., and AdolF Schotr, M.D., M.R.C.S. Pp. xv + 531, with 212 illustrations. London: Wm. Heinemann. 1953. $€ 55 \mathrm{~s}$.

It is an advantage in every subject to have a complete reference book. In this small field here is a book to end all reference books. Every aspect of extrasystoles is covered from the historical and investigative viewpoints to therapy. In fact, it is so full and wordy that it is almost impossible to read more than a short section at a time. One is constantly amazed at the thoroughness of the authors in their task. However, one feels that it can only find a place in the libraries of few specialized centres and many cardiologists may feel that five guineas is too much for even such a complete review of so small a branch of their subject, especially as some of the E.C.G.s are so poorly reproduced.

\section{A HANDBOOK ON CANCER FOR NURSES AND HEALTH VISITORS}

By Ronald W. Raven, O.B.E., F.R.C.S. Pp. viii + ro4, with 21 illustrations. London: Butterworth \& Co. 1953. r2s. 6 d.

This reasonably priced book presents clearly and simply just the information a student nurse needs to know about the important subject of malignancy. A sound introduction is made with a description of a normal cell, before noting its change into an $N$ abnormal one. Study of the disease is taken into $\omega$ the wider field of the care of the sick in their own homes, considering especially the problems of the if chronic sick, and their need of attention by night as $N$ well as by day. The link with the social services is good. Excellent photographs illustrate particular cases.

I recommend the book unreservedly to all student nurses to read in conjunction with general textbooks on medicine and surgery.

\section{INFLUENZA}

By C. H. Stuart-HaRris, M.D., F.R.C.P. Pp. 235, with 94 illustrations. London: Edward Arnold \& Co. 1953. 30s.

Infections of the respiratory tract bulk largely in the catalogue of human illness and perhaps the most $\mathbb{D}$ numerous of these are due to viruses. Yet, for many, knowledge of these conditions is inexact and the label ' $\mathrm{flu}$ ' is attached haphazardly to any seasonal infection. Of recent years there has been much accumulation of knowledge of the epidemiology and laboratory diagnosis of influenza and this book does much to clarify the situation with an up to date account of what is known and what is speculative and of present research into virus infections of the respiratory tract.

The book is divided into two halves, the first half devoted to influenza and the second to other infections of the respiratory tract of virus origin. In the chapters on influenza an unusually good balance $\frac{D}{2}$ is maintained between the clinical aspects of the disease and the pathology and epidemiology. The $\mathrm{N}$ clinical picture is fully described with typical case $\odot$ histories and there is an informative chapter on the $\mathrm{N}$ pulmonary complications with numerous well re- N produced X-rays. The pathology is discussed both $\sigma$ in man and the experimental animal and the bacteriology reviewed in the light of recent out- $\frac{O}{5}$ breaks. The epidemiology is interestingly pre- $\mathbb{D}$ sented and epidemics in different parts of the world $\stackrel{+}{+}$ are discussed with relation to different virus strains $T$ and to varying mortality and attack rate. There is . 